\title{
Fetal and maternal outcome in oligohydramnios pregnancy (37-40 weeks)
}

\author{
Suyajna D. Joshi, Ruksar Banu*, Rajeswari Rai, Jayasakthi G.
}

Department of DNB-OBG, District Hospital Ballari, Karnataka, India

Received: 02 December 2020

Revised: 07 January 2021

Accepted: 08 January 2021

\author{
*Correspondence: \\ Dr. Ruksar Banu, \\ E-mail: drrukarbanu@gmail.com.com
}

Copyright: (c) the author(s), publisher and licensee Medip Academy. This is an open-access article distributed under the terms of the Creative Commons Attribution Non-Commercial License, which permits unrestricted non-commercial use, distribution, and reproduction in any medium, provided the original work is properly cited.

\begin{abstract}
Background: This study is conducted to see the effects of oligohydramnios on both mother and fetus.

Methods: 237 antenatal patients delivered at Department of DNB-OBG District hospital Bellari during January 2018 to December 2018 with gestational age between $37-40$ wks with AFI $<5 \mathrm{cms}$ with intact membranes were studied and analyzed retrospectively for perinatal and maternal outcome.

Results: Out of 237 cases with oligohydramnios with AFI $<5 \mathrm{~cm}$ studied, about 229 cases underwent LSCS (96.6\%). most are primigravida about 164(69.19\%), belong to age group of $<25$ about $181(76 \%)$. Average gestational age noted to be $38+4$ weeks about $55.9 \%$ (132), NICU admission seen in 47(19.8\%) of total cases. Most of the babies delivered are $>2.5 \mathrm{~kg}$ birth weight about 144 (60.75\%) of cases. New born with APGAR <7 @ 1 min seen in 36 cases $(15.15 \%)$. Meconeum stained liquor seen in about 70 cases $(29.5 \%)$.

Conclusions: Oligohydramnios has significant correlation with increased Caesarean section for fetal distress. Oligohydramnios is associated with high rate of pregnancy complication and increased rate of NICU admission. Oligohydramnios is a frequent occurrence demanding careful evaluation, intensive fetal surveillance and proper antepartum and intrapartum care.
\end{abstract}

Keywords: AFI, Fetal Distress, Oligohydramnios LSCS

\section{INTRODUCTION}

Amniotic fluid provides a protective environment for fetal growth, acting like a cushion for the fetus and protecting against mechanical and biological injuries. And it provides nutrients essential for the growth, also provides space for adequate movements and proper development. ${ }^{1}$ Amniotic fluid is important for the normal development respiratory, genitourinary, gastrointestinal, and musculoskeletal system.

With gestational age Amniotic fluid volume changes, it is $50 \mathrm{ml}$ at 12 weeks increases to around $400 \mathrm{ml}$ at midpregnancy and maximum of $1000 \mathrm{ml}$ at term, and decreases after.
Liquor volume below the $5^{\text {th }}$ percentile for that gestational age is considered as oligohydramnios. Early onset of oligohydramnios usually are reported to be associated with congenital fetal anomalies, such as dysplastic kidney, bladder outlet obstruction, bilateral renal agenesis, pulmonary hypoplasia, bilateral multicystic kidney etc, with poor fetal outcomes as Intrauterine growth restriction, fascial distortion and multiple structural deformities. ${ }^{2,3}$ Late onset oligohydramnios are mostly related to umbilical cord compression and thick meconium liquor, and these women are more likely to be affected by placental abnormality or maternal complications such as preeclampsia or vascular diseases. ${ }^{1}$ 
The objective of the study was to study various maternal and fetal outcome in pregnancy with oligohydramnias.

\section{METHODS}

The present study was Retrospective observational study conducted in the Department of Obstetrics and Gynecology, District Hospital Bellary. During Period of January 2018 to December 2018

In this study, All pregnant women with term pregnancy admitted to labour room who fulfill's the inclusion criteria and willing to participate will be selected for the study .Feto maternal outcome will be studied in different volumes of Amniotic Fluid.

\section{Inclusion criteria}

Women with singleton pregnancy, non-anomalous fetus, intact membranes Gestational age $37-40 \mathrm{wks}$, AFI $<5 \mathrm{~cm}$

\section{Exclusion criteria}

Women with premature rupture of membranes, Known fetal and chromosomal anomaly, Severe pre-eclampsia, post-term pregnancy.

On admission a detailed history was taken, clinical examination was performed and gestational age assessed.AFI was determined by trans-abdominal sonography. AFI was measured by dividing the uterus into four quadrants. NST was performed for all patients. Parameters noted were MSAF, the mode of delivery, birth weight,

Apgar score at 1 and 5minutes. The ethical committee of institute had approvedthe study. Results were analysed with special emphasis on maternal and perinatal outcome by using percentage calculator and proportion.

\section{RESULTS}

It was observed that $181(76 \%)$ women with oligohydramnios were in age group of 20-25 years.

By parity $69.19 \%$ were primigravida. $29.4 \% \%$ were multigravida.

Table 1: Age and oligohydramnios.

\begin{tabular}{|lll|}
\hline Age group & Numbers & Percentage \\
\hline $\mathbf{2 0 - 2 5}$ & 181 & 76 \\
\hline $\mathbf{2 6 - 3 0}$ & 51 & 22 \\
\hline $\mathbf{3 0}$ & 5 & 2.1 \\
\hline
\end{tabular}

By gestational age more commonly olighydramnias seen in GA 39 week with 0 days to 39 weeks with 6 days $(55.9 \%) 132$ cases.
Table 2: Obstetric score and oligohydramnios.

\begin{tabular}{|lll|}
\hline Gravida & Numbers & Percentage \\
\hline $\mathbf{1}$ & 164 & 69.19 \\
\hline $\mathbf{2}$ & 45 & 18.98 \\
\hline $\mathbf{3}$ & 20 & 8.43 \\
\hline $\mathbf{4}$ & 7 & 2.95 \\
\hline $\mathbf{5}$ & 1 & 0.42 \\
\hline
\end{tabular}

Table 3: Gestational age and oligohydramnios.

\begin{tabular}{|lll|}
\hline Gestational age & Numbers & Percentage \\
\hline 37+0day-37+6day & 50 & 21.09 \\
\hline 38+0day-38+6day & 55 & 23.20 \\
\hline 39+0day-39+6day & 132 & 55.9 \\
\hline
\end{tabular}

Table 4: Severity of oligohydramnios.

\begin{tabular}{|lll|}
\hline AFI & Numbers & Cases $(\%)$ \\
\hline $\mathbf{0}$ & 22 & 9.28 \\
\hline $\mathbf{1}$ & 3 & 1.20 \\
\hline $\mathbf{2}$ & 7 & 2.90 \\
\hline $\mathbf{3}$ & 2 & 0.80 \\
\hline $\mathbf{4}$ & 3 & 1.20 \\
\hline $\mathbf{5}$ & 124 & 52.32 \\
\hline $\mathbf{5 - 8}$ & 76 & 32.06 \\
\hline
\end{tabular}

$52.32 \%$ patients have AFI-5 and $9.28 \%$ patients have AFI-0.

Table 5: Colour of liquor at the time of rupture of membranes.

\begin{tabular}{|lll|}
\hline Colour of liqour & Numbers & Percentage \\
\hline Meconeum & 70 & 29.5 \\
\hline Clear & 167 & 70.5 \\
\hline
\end{tabular}

Table 6: Mode of delivery.

\begin{tabular}{|lll|}
\hline Mode of delivery & Numbers & Percentage \\
\hline LSCS & 229 & 96.60 \\
\hline FTND & 8 & 3.30 \\
\hline
\end{tabular}

Table 7: Birth weight.

\begin{tabular}{|lll|}
\hline Birth weight & Numbers & Percentage \\
\hline$<\mathbf{2 . 5} \mathbf{~ k g}$ & 93 & 39.24 \\
\hline $\boldsymbol{2} \mathbf{2 . 5} \mathbf{~ k g}$ & 144 & 60.7 \\
\hline NICU admission & 47 & 19.80 \\
\hline
\end{tabular}

Table 8: APGAR score.

\begin{tabular}{|lll|}
\hline APGAR & Numbers & Percentage \\
\hline <7@ 1 Min & 36 & 15.15 \\
\hline <7@5 Min & 29 & 12.20 \\
\hline
\end{tabular}




\section{DISCUSSION}

Out of 237 cases with oligohydramnios with AFI $<5 \mathrm{~cm}$ studied, about 229 cases underwent LSCS (96.6\%). most are primigravida about $164(69.19 \%)$, belong to age group of $<25$ about $181(76 \%)$. Average gestational age noted to be $38+4$ weeks about $55.9 \%$ (132), NICU admission seen in $47(19.8 \%)$ of total cases. Most of the babies delivered are $>2.5 \mathrm{~kg}$ birth weight about 144 $(60.75 \%)$ of cases. Newborn with APGAR $<7 @ 1$ min seen in 36 cases $(15.15 \%)$. Meconeum stained liquor seen in about 70 cases $(29.5 \%)$.

Majeed et al the mean age of the women with oligohydramnios was $26.10 \pm 5.20$ years ranged between 16 and 40 . The mean age of the gestational age was 38.54 \pm 1.13 weeks ranging from 37 to $40 .^{4}$ The previous history of a dead newborn was so low (mean: $0.02 \pm 0.14$ ). Half of the patients delivered their pregnancies by caesarean section $(\mathrm{C} / \mathrm{S})(50.5 \%)$, and most of them had a good Apgar score value (98.8\%).The study showed that women who had a past medical history or delivered by $\mathrm{C} / \mathrm{S}$, their newborns were more likely to admit to neonatal intensive care unit (NICU), $36.8 \%$ versus $12.1 \%$ $(\mathrm{p}=0.017)$ and $78.9 \%$ versus $21.1 \% \quad(\mathrm{p}=0.010)$, respectively.

Figueroa et al of 12,940 women enrolled in the clusters in Guatemala, Pakistan, Zambia and the DRC in the First Look Studywho had a third trimester ultrasound examination, 87 women were diagnosed with oligohydramnios, equivalent to $0.7 \%$ of those studied. ${ }^{5}$ Prevalence of detected oligohydramnios varied among study sites; from the lowest of $0.2 \%$ in Zambia and the DRC to the highest of $1.5 \%$ in Pakistan. Women diagnosed with oligohydramnios had higher rates of haemorrhage, fetal malposition, and caesarean delivery than women without oligohydramnios. Unfavourable fetal and neonatal outcomes associated with oligohydramnios including stillbirths (OR 5.16, 95\% CI $2.07,12.85)$, neonatal deaths $<28$ days (OR $3.18,95 \% \mathrm{CI}$ $1.18,8.57)$, low birth weight (OR 2.10, 95\% CI 1.44, 3.07 ) and preterm births (OR 2.73, 95\% CI 1.76, 4.23). The mean birth weight was $162 \mathrm{~g}$ less $(95 \% \mathrm{CI}-288.6$, -35.9 ) with oligohydramnios.

Srilakshmi et al out of the 200 women, included in the present study, in study group AFI $<5 \mathrm{~cm}$ was present in $51 \%$ of patients and AFI $5-8 \mathrm{~cm}$ in $49 \%$ of patients. ${ }^{6}$ Doppler abnormalities found in study group $(n=33) .32 \%$ of the patients in study group had non-reactive NST while in control group $8 \%$. Caesarean section was performed in $70 \%$ of cases in study group as compared to $9 \%$ in control group. Fetal distress was the most common indication for LSCS. There were no perinatal deaths in this study.

Jagatia et al mean maternal age-23.66 years. Incidence of oligohydramnios was more in primi-para $(52 \%)$ in our study. ${ }^{7}$ And operative morbidity was also more in primipara. Most common cause of Oligohydramnios is idiopathic $(52 \%)$. Second commonest cause is $\mathrm{PIH}$ (25\%). Operative morbidity is highest in PIH $(60 \%)$. Operative morbidity was significantly higher in NST (non-stress test) non-reactive $(3.12 \pm 75=78.12 \%)$ group than NST reactive $(26.47 \%)$ group. Most common reason to perform caesarean was fetal distress which was either due to cord compression or IUGR. $7 \%$ patients were found with feto placental insufficiency on Doppler study. Oligohydramnios was related to higher rate of growth retardation and NICU (neonatal intensive care unit) admission.

Radhamani et al, a total of 130 cases of isolated oligohydramnios were assessed. $55.4 \%$ had vaginal delivery. ${ }^{8} 13.8 \%$ underwent elective LSCS and $30.8 \%$ had emergency LSCS. $18.5 \%$ had meconium stained liquor, $4.6 \%$ babies had APGAR of $<7$ at 5 minutes. $17.7 \%$ had birth weight of $<2.5 \mathrm{~kg}$ and $6.9 \%$ of babies required NICU admission.

Ahmar et al mean maternal age-26.1 years. Incidence of oligohydramnios was more in primipara $(64.4 \%)$ in this study. ${ }^{9}$ And operative morbidity was also more in primipara $(51.7 \%)$. Most common cause of Oligohydramnios was idiopathic $(44.44 \%)$. Operative morbidity was significantly higher in Non-reassuring FHR $(80 \%)$ than reassuring FHR $(32 \%){ }^{7}$ patients $(7.78 \%)$ were found with feto-placental insufficiency on Doppler study.

Chaudhari et al, the Caesarean section rate for fetal distress was $41 \%$ in patients with Oligohydramnios. ${ }^{10}$ Meconium staining of amniotic fluid was found in $30.7 \%$ patients. APGAR score at 5 minutes $<7$ was found in 6 patients $(3.8 \%)$.

Ghosh et al $65.5 \%$ participants were belonged to 20 to 25 age group and $35.5 \%$ participants were Primigravida. ${ }^{11}$ Mean age was $23.9 \pm 3.3$ years and mean gestation age was 36.9 week. Almost $72.2 \%$ were in 34 to 37 weeks of gestational age. Study found FMC $<10$ in $56.4 \%$ of participants. Forty percent participants have AFI 4 and $27.3 \%$ have AFI 5. $47.3 \%$ delivery was done by vaginal route. $5.5 \%$ baby was still birth and prematurity were the most common cause of still birth. Around $71 \%$ babies were low birth weight and congenital anomalies were present in $7.3 \%$ babies. APGAR score measured $<7$ at 1 minute was in $65.4 \%$ and $<7$ at 5 minutes was in $43.6 \%$ babies.

\section{CONCLUSION}

Amniotic fluid acts as a predictor of fetal tolerance in labour and its decrease in amount is associated with increased risk of abnormal NST and meconium stained fluid. Due to intrapartum complication and high rate of perinatal morbidity and mortality, rates of caesarean section are rising, but decision between vaginal delivery and caesarean section should be well balanced so that 
unnecessary maternal morbidity can be prevented and timely intervention can reduce perinatal morbidity and mortality.

Oligohydramnios is a frequent occurrence demanding careful evaluation, intensive fetal surveillance and proper antepartum and intrapartum care.

Funding: No funding sources

Conflict of interest: None declared

Ethical approval: The study was approved by the Institutional Ethics Committee

\section{REFERENCES}

1. Dashe JS, Bloom SL, Spong CY, Hoffman BL. Amniotic fluid. Williams Obstetrics. $24^{\text {th }}$ ed New York: McGraw Hill Professional; 2018.

2. Visvalingam G, Purandare N, Cooley S, Roopnarine singh R, Geary M. Perinatal outcome after ultrasound diagnosis of anhydramnios at term. J Obstet Gynaecol. 2012;32:50-3.

3. Ghimire S, Ghimire A, Chapagain S, Paudel S. Pregnancy outcome in cases of oligohydramnios after 28 weeks of gestation. Int $\mathbf{J}$ Adv Med Health Res. 2016;3:68.

4. Majeed HA, Shamdeen MY. Fetal and Maternal Outcomes in Oligohydramnios Pregnancy (37-40 Weeks of Gestation) at Labor available at http://www.medjbabylon.org.

5. Figueroa L, McClure EM, Swanson J, Nathan R, Garces AL, Moore JL, et al. Oligohydramnios: a prospective study of fetal, neonatal and maternal outcomes in low-middle income countries. Reproductive. 2020;17:19.

6. Sreelakshmi U, Bindu T, Subhashini T. Impact of oligohydramnios on maternal and perinatal outcome: a comparative study Int $\mathbf{J}$ Reprod Contracept Obstet Gynecol. 2018;7(8):3205-10.

7. Jagatia K, Singh N, Patel S. Maternal and fetal outcome in oligohydramnios: a study of 100 cases. International J Medic Science Public Health. 2013;2: 3.

8. Babitha RS. A clinical study of feto-maternal outcome in pregnancies with oligohydramnios Int $\mathbf{J}$ ReprodContraceptObstet Gynecol. 2017;6(3):868-71.

9. Ahmar R, Parween S, Kumari S, Kumar M. Neonatal and maternal outcome in oligohydramnios: a prospective study Int $\mathbf{J}$ Contemp Pediatr. 2018;5(4):1409-13.

10. Chaudhari KR, Chaudhari KR, Desai OM. Perinatal outcome associated with oligohydramnios in third trimester Int J Reprod Contracept Obstet Gynecol. 2017;6(1):72-5.

11. Ghosh R, Oza H, Padhiyar B. Maternal and fetal outcome in oligohydramnios: study from a tertiary care hospital, Ahmedabad, India Int J Reprod Contracept Obstet Gynecol. 2018;7(3):907-10.

Cite this article as: Joshi SD, Ruksar B, Rai R, Jayasakthi G. Fetal and maternal outcome in oligohydramnios pregnancy (37-40 weeks). Int J Reprod Contracept Obstet Gynecol 2021;10:605-8. 